\title{
The effect of fertilizers on the fertility of leached chernozem in different technologies
}

\author{
O.V. Volynkina*
}

FSBNU "Ural Federal Agrarian Research Center of the Ural Branch of the Russian Academy of Sciences", 641325 Sadovaya village, Ketovsky r-n, Kurgan region,str. Lenin 9, Russia

\begin{abstract}
The article shows the effective and potential fertility of leached low-humus, low-power medium-loamy chernozem under the conditions of a stationary field experiment at the Central Experimental Field of the Kurgan Research Institute. Two technologies are characterized. In the first part of the experiment, the crop rotation is corn-wheat-wheat-oats with annual plowing, in the second part-permanent wheat on a stubble background. The first technology was distinguished by a higher effective fertility, a large number of plant residues, due to which its advantage was manifested in the content of humus. The fertilizer increased the productivity of agricultural crops. In increasing crop yields, the use of N40P20 was economically and environmentally optimal. The positive effect of fertilizers on the humus content in the soil layer of $0-20 \mathrm{~cm}$ was manifested when applying N50-75P in the first part of the experiment and N40-60P20 in second part, which was not observed with unilateral nitrogen fertilizer and the use of dozes N25-20P.
\end{abstract}

\section{Introduction}

The stability over time of optimal levels of agrochemical indicators of soil fertility stabilizes the productivity of agricultural crops. It is important to know how manageable and regulated those signs that are closely related to yield are. Fertilizers significantly improved the conditions of nitrogen and phosphorus nutrition of plants, increasing the content of mobile nutrients in the soil. Special attention is paid effect fertilizers on the content of organic matter in the soil, which is represented by humus and residues of plant and animal origin of varying degrees of decomposition. The relationship of plant productivity with this indicator is also manifested, both directly and indirectly. In agrocenoses, along with the mineralization of the easily mobile part of humus, its reserve is replenished due to the transformation of residues. The balance of these processes contributes to the preservation of the humus content. In other cases, there is a decrease or increase in the percentage of humus. All three situations are noted in the literature. On ordinary chernozem in the experiments of N. N. Shapovalova and E. P. Shustikovaya [1] without fertilizer at the initial humus content of $3.38 \%$ after 5 years, a decrease of 0.04 percentage points was manifested, and after 32 years by 0.92 . The use of fertilizer at a dose of $\mathrm{N} 30 \mathrm{P} 30$ reduced losses to -0.46 and with full mineral fertilizer-to -0.36 . Unilateral

\footnotetext{
${ }^{*}$ Corresponding author: volynkina.o@bk.ru
} 
application of N150 or P30-90 caused a decrease in yield and loss of size- $0.74-0.82 \%$. The increase content of humus to $3.94 \%$ was provided by the fertilizer N150P120K120. Other researchers also point out similar patterns [2-4].

An increase in the humus content due to manure and complete mineral fertilizer has been shown in Krasnoyarsk studies, in the experiments of the Don and Voronezh State Agrarian University, the Belgorod Research Institute of Agriculture, the SibNII of Agriculture and the chemization of agriculture [5-9]. Several important factors of the variability of the humus content were captured. Thus, N. A. Chuyan and G. M. Breskina [10] believe that a type of organic fertilizer - manure or straw-contributes to this indicator by $22 \%$. The latter acts more strongly. The depth of sampling changes the result of the determination by $33 \%$.

The type of tillage has a certain effect on the humus content. In the experiments of Omsk scientists V. G. Kholmov and M. I. Shulyakov [11], the rate of loss of the humus stock with minimal processing was reduced by half in relation to plowing. On dark gray soil in the experiments of Orel researchers L. A. Nechaev and co-authors [12], surface treatment provided an increase in humus for plowing in layers of $0-10$ and $10-20 \mathrm{~cm}$, and there were no differences in the layer of $20-30 \mathrm{~cm}$. Sokolov and co-authors [13] noticed that the labile fraction of humus under zero treatment is localized in a layer of $0-10 \mathrm{~cm}$, and against the background of plowing - at the depth of plowing of plant residues.

In the stationary experiment of P. P. Vasyukov and co-authors [14] on the leached chernozem of the Krasnodar Territory, since 2006, changes in the humus state of the soil have been monitored for three types of tillage. In the crop rotation with sunflower and corn for grain without steam, the traditional tillage system maintained or slightly increased the percentage of humus from the initial value of 3.60 to $3.70-4.03$. The systems is minimally mulching and the same with decompression gave the readings above- 4,06-4,17-4,25\%, which was explained by the different rate of decomposition of the residues. In a model experiment on a typical chernozem since 2012, the transformation of residues has been traced. During the year, winter wheat straw decomposed by $25 \%$ and then in two years by 72 and $87 \%$. The rate of decomposition of sunflower stems and roots over these 3 years was different: 45,73 and $90 \%$ [15].

In stationary experiments, the course of changes in the humus content in the soil is studied more strictly with the simultaneous search for optimal doses of fertilizers to stabilize its level and crop productivity, in such experiments the manifestation of random factors decreases. In field research, it is possible to select methods of chemical analysis of soil and plants for the diagnosis of mineral nutrition conditions, the development of security indices, coefficients of the use of nutrients from soil and fertilizers, which is necessary for the stage of implementing the conclusions of experiments in production conditions. At the same time, the scales of plant nutrient supply are specified. The content of mobile nutrients in the soil is entirely determined by the agrotechnical and bioclimatic potential [16].

The purpose of the article is to show the results of observations of the effective and potential soil fertility in two agrocenoses in a stationary experiment of the Kurgan Research Institute of Agricultural Sciences.

\section{Materials and methods}

The Kurgan region is located in the south-eastern zone of the West Siberian Lowland. It borders the Sverdlovsk Region in the northwest, Chelyabinsk Region in the west, Tyumen Region in the east, and Kazakhstan in the south and southeast. The diversity of soil and climatic conditions in the zones of the Kurgan region is quite obvious, which was caused by the organization at the Kurgan Research Institute of Agriculture of four experimental fields. The article contains materials obtained at the Central Experimental Field of the Kurgan Research Institute. The research was carried out at the Kurgan Research Institute of 
Agriculture-a branch of the URFANITS Ural Branch of the Russian Academy of Sciences in the laboratories of agrochemistry and agriculture within the framework of the State Task of the Ministry of Science and Higher Education on the topic No. 0532-2021-0002 "To improve the system of adaptive landscape farming for the Ural region and create a new generation of agricultural technologies based on minimizing soil cultivation, crop rotation diversification, rational use of pesticides and biological products, preserving and increasing soil fertility and to develop an information and analytical complex of computer programs that provides innovative management of the farming system". In the first part of the stationary experiment, there was a corn-wheat-wheat-oat crop rotation during annual plowing (1971-1998), in the second-permanent wheat on stubble (1999-2020). The objects of observation are leached low-power low-humus medium-loamy chernozem; two technologies for cultivating crops and a set of options with different fertilizer composition and nitrogen doses (N25-50-75 in rotation and N20-40-60 at permanent wheat. The study of such a technology was required, since in the Kurgan region over the past 20 years, up to $50 \%$ of grain crops were placed on a stubble background. The experiment was founded by V. I. Volynkin in 1971, the performer of the experiment has been the author of the article since 1993. Straw has been left on the field since 1978-since the use of the Sampo-500 combine. Agrochemical properties of leached chernozem: $\mathrm{pH}_{\mathrm{KCl}} 6.2-6.5$ at the beginning of the experiments and 5.2-5.5 at present, humus according to Tyurin $4.4 \%$, total nitrogen according to Kjeldahl $0.20 \%$, total phosphorus $0.07 \%$, the sum of absorbed Ca and $\mathrm{Mg} 20$ $22 \mathrm{meq} / 100 \mathrm{~g}$ (according to Cappen). The content of mobile phosphorus and exchangeable potassium according to Chirikov in the soil layer of $0-20 \mathrm{~cm}$ on the site under the experiment is $40-50$ and $250-350 \mathrm{mg} / \mathrm{kg}$. Observations of the variability in time and from fertilizers of such soil properties as humus, the amount of absorbed bases and soil acidity were carried out periodically, mobile nutrients were determined annually. Fertilizers ammonium nitrate and ammophos were introduced in the spring before sowing locally with a seeder SZ-3,6.

The place of research is the Central experimental field of the Kurgan Research Institute. The characteristic of weather conditions is of crucial importance for explaining the size of the crop. Periodically recurring May and June droughts are a typical phenomenon for the Trans-Urals. In the central zone of the Kurgan region, the annual precipitation is 350-369 $\mathrm{mm}$, during the growing season 190-207 $\mathrm{mm}$. The duration of the period with a temperature of $10^{\circ} \mathrm{C}$ is $130-134$ days, at the beginning of the onset of such a temperature, the average supply of productive moisture in the meter-long soil layer is $110-150 \mathrm{~mm}$. The total area of the plot is $270 \mathrm{~m} 2$, the accounting area is $90 \mathrm{~m} 2$. The repetition of the variants is threefold. Zoned varieties of crops were sown. Accounting of the corn crop was carried out by mowing the plants of the site of $14 \mathrm{~m} 2$, weighing and determining the moisture content of the mass. Grain crops were mowed directly by a Sampo-500 combine harvester with a sample selection for analysis for humidity and weediness. The crop is brought to $14 \%$ humidity and $100 \%$ purity. The amount of plant residues was calculated: for straw from sheaves taken before harvesting, for roots and stubble - according to the TSINAO method [17]. The preservation of humus in the grain agrocenosis depends on the amount of fresh plant residues and their composition [18].

\section{Results}

The productivity of the two studied agrocenoses differed significantly. The crop yield in the crop rotation under the conditions of annual plowing was significantly higher than in the second part of the experiment - on permanent wheat on a stubble background (Table. 1 and 2). 
Table 1. Characteristics of agrocenosis productivity in grain crop rotation, 1971-1998.

\begin{tabular}{|c|c|c|c|c|c|c|c|}
\hline \multirow[b]{2}{*}{ Variant } & \multicolumn{5}{|c|}{ Yield, $\mathrm{t} / \mathrm{ha}$ f. units. } & \multirow[b]{2}{*}{$\begin{array}{l}+- \text { to } \\
\text { control }\end{array}$} & \multirow[b]{2}{*}{$\begin{array}{c}\text { Payba } \\
\mathrm{ck}, \\
\mathrm{kg} / \mathrm{kg}\end{array}$} \\
\hline & maize & $\begin{array}{c}1 \text { st and } 2 \mathrm{nd} \\
\text { wheat for } \\
\text { maize, average }\end{array}$ & oats & $\begin{array}{l}\text { per crop } \\
\text { rotation }\end{array}$ & $\begin{array}{l}\text { averag } \\
\text { e per } \\
\text { year }\end{array}$ & & \\
\hline Control & 3,85 & 1,86 & 2,38 & 9,95 & 2,49 & - & - \\
\hline N25 & 4,47 & 2,10 & 2,52 & 11,19 & 2,80 & $0,3,1$ & 12,4 \\
\hline N50 & 4,71 & 2,16 & 2,56 & 11,59 & 2,90 & 0,41 & 8,2 \\
\hline N75 & 4,75 & 2,09 & 2,49 & 11,42 & 2,86 & 0,37 & 4,9 \\
\hline $\mathrm{N} 25 \mathrm{P} 40$ & 4,93 & 2,34 & 2,87 & 12,48 & 3,12 & 0,63 & 8,4 \\
\hline N50 P40 & 5,76 & 2,54 & 2,84 & 13,68 & 3,42 & 0,93 & 10,3 \\
\hline N75 P40 & 5,96 & 2,45 & 2,83 & 13,68 & 3,42 & 0,93 & 8,1 \\
\hline $\mathrm{SSD}_{05}$ & 0,95 & $0,20-0,27$ & 0,13 & & & $0,19-0,34$ & \\
\hline
\end{tabular}

Table 2. Characteristics of agrocenosis productivity of permanent wheat by stubble, 1999-2020 years.

\begin{tabular}{|l|c|c|c|}
\hline \multicolumn{1}{|c|}{ Variant } & Yield, $\mathrm{t} / \mathrm{ha}$ & + - To control & Payback, kg/kg \\
\hline Control & 0,98 & - & - \\
\hline N20 & 1,16 & 0,18 & 9,0 \\
\hline N40 & 1,23 & 0,25 & 6,2 \\
\hline N60 & 1,20 & 0,22 & 3,7 \\
\hline N20P20 & 1,32 & 0,34 & 8,5 \\
\hline N40P20 & 1,52 & 0,54 & 9,0 \\
\hline N60P20 & 1,64 & 0,66 & 8,2 \\
\hline SSD05 & & $0,12-0,31$ & \\
\hline
\end{tabular}

The differences affected the number of plant residues, which is higher in the first part of the experiment. The humification coefficient is 0,15 for wheat and 0,10 for maize [17]. On average, over the 50 years of the experiment, the balance of humified organic matter was positive in all versions, differing in magnitude. Only nitrogen-phosphorus fertilizer at the doses $\mathrm{N} 50-75 \mathrm{P} 40$ at the grain crop rotation and N40-60P20 on permanent wheat by stubble had a significant positive effect on the balance of OMg (Table 3)

Table 3. Effect of fertilizer composition and nitrogen doses on plant residues and $\mathrm{OB}_{\mathrm{G}}$ balance.

\begin{tabular}{|l|c|c|c|c|c|c|}
\hline \multirow{2}{*}{ Variant } & \multicolumn{2}{|c|}{ Number of plant residues, $\mathrm{t} / \mathrm{ha}$} & \multicolumn{3}{c|}{$\mathrm{OV}_{\mathrm{G}}$ balance per year, $\mathrm{t} / \mathrm{ha}$} \\
\cline { 2 - 7 } & $\begin{array}{c}\text { 1st part of } \\
\text { the } \\
\text { experience, } \\
28 \text { years }\end{array}$ & $\begin{array}{c}\text { 2nd part } \\
\text { experience, } \\
\text { 22 years }\end{array}$ & $\begin{array}{c}\text { weighted } \\
\text { average } \\
\text { over 50 } \\
\text { years }\end{array}$ & $\begin{array}{c}\text { 1st part of } \\
\text { the } \\
\text { experience, } \\
28 \text { years }\end{array}$ & $\begin{array}{c}\text { 2nd part } \\
\text { experience, } \\
\text { 22 years }\end{array}$ & $\begin{array}{c}\text { weighted } \\
\text { average } \\
\text { over 50 } \\
\text { years }\end{array}$ \\
\hline Control & 3,77 & 2,99 & 3,43 & 0,02 & $-0,13$ & $-0,05$ \\
\hline N40 & 4,02 & 3,77 & 3,91 & 0,10 & 0,08 & 0,09 \\
\hline N25-20P40-20* & 4,68 & 3,84 & 4,31 & 0,16 & 0,16 & 0,16 \\
\hline N50-40P40-20 & 4,97 & 4,49 & 4,76 & 0,21 & 0,27 & 0,23 \\
\hline N75-60P40-20 & 5,18 & 4,80 & 5,01 & 0,24 & 0,35 & 0,29 \\
\hline SSD $_{05}$ & 0,75 & 0.83 & & 0,15 & 0,14 & \\
\hline
\end{tabular}

* The first doses are in crop rotation, the second - on permanent wheat.

At wide-row crops of corn on green material the quantity of the remains are lower, and their mineralization is higher - at coefficient 0.0095 unlike 0.0045 for grain crops. In addition, the first 7 years of the crop rotation, the straw was removed from the field. Therefore at permanent cultivation of wheat in balance of OMg the small advantage in versions with fertilizer was shown. In the maintenance of a humus the saving the contents of a humus in control is noted. In options with fertilizer already by the end of the first decade of their application in days of a crop rotation when plowing the accurate regularity 
of increase in percent of a humus in two of them was designated. Reliable increase belonged to application of N50-75P40. Indicators of maintenance of a humus varied according to changes of productivity. So, after receiving a big crop of wheat in $1985(1,8$ $\mathrm{t} /$ hectare in control and 30 in variant N50P40) the definitions of humus 1987 year are much higher. After droughty 1992 with productivity of 1,2-1,8 t/hectare the indicators of the following analyses are lower. In further definitions on permanent wheat on an eddish positive action introduction of N40-60P20 (table 4).

Table 4. A dose of nitrogen and the maintenance of a humus in a soil layer of $0-20 \mathrm{~cm}, \%$.

\begin{tabular}{|l|c|c|c|c|c|c|c|}
\hline $\begin{array}{c}\text { Year/ } \\
\text { Variant }\end{array}$ & 1982 & 1987 & 1990 & 1993 & 1994 & 1995 & Average \\
\hline \multicolumn{7}{|c|}{ In grain crop rotation } \\
\hline Control & 4,35 & 4,94 & 4,58 & 4,45 & 4,38 & 4,25 & 4,49 \\
\hline N50 & 4,23 & 4,62 & 4,70 & 4,60 & 4,48 & 4,38 & 4,42 \\
\hline N25P40 & 4,26 & 5,60 & 4,72 & 4,97 & 4,38 & 4,25 & 4,70 \\
\hline N50P40 & 5,27 & 5,63 & 5,17 & 5,03 & 5,40 & 4,97 & 5,24 \\
\hline N75P40 & 5,08 & 6,67 & 5,05 & 5,26 & 5,28 & 4,97 & 5,38 \\
\hline \multicolumn{7}{|c|}{ Permanent wheat by stubble } \\
\hline Year & 2006 & 2008 & 2011 & 2012. & 2016 & 2020 & \\
\hline Control & 4,64 & 4,43 & 4,39 & 4,70 & 4,35 & 4,75 & 4,54 \\
\hline N40 & 4,78 & 4,64 & 4,45 & 4,48 & 4,48 & 4,78 & 4,60 \\
\hline N20P20 & 4,68 & 4,23 & 4,31 & 4,48 & 4,35 & 4,76 & 4,47 \\
\hline N40P20 & 5,14 & 4,64 & 4,56 & 4,82 & 4,99 & 5,56 & 4,95 \\
\hline N60P20 & 5,39 & 5,07 & 4,70 & 5,69 & 4,99 & 5,59 & 5,24 \\
\hline SSD 5 & 0,$4 ;$ Ffact $=2,40 ;$ Ftable $=0,26$ \\
\hline
\end{tabular}

Observations of acidity of the soil showed that use of nitrogen and phosphoric fertilizers didn't cause big change of acidity of the lixivious chernozem. The time factor was stronger. The regularity of small strengthening of acidity is found in N75-60P option (tab. 5). The same time, the $\mathrm{pH}$ of the water extract in 2016 year remained at the initial level.

Table 5. Influence of systems of fertilizer on pHkcl in a soil layer of $0-20 \mathrm{~cm}$.

\begin{tabular}{|l|c|c|c|c|c|c|c|c|c|}
\hline Year/ Variant & 1992 & 1994 & 1995 & 2006 & 2008 & 2011 & 2012 & 2016 & 2020 \\
\hline N0P0 & 5,40 & 5,50 & 5,30 & 5,41 & 5,20 & 5,34 & 5,34 & 5,61 & 5,21 \\
\hline N25-20P & 5,40 & 5,40 & 5,40 & 5,39 & 5,08 & 5,34 & 5,17 & 5,57 & 5,31 \\
\hline N50-40P & 5,35 & 5,20 & 5,30 & 5,32 & 5,09 & 5,20 & 5,07 & 5,42 & 5,24 \\
\hline N75-60P & 5,25 & 5,30 & 5,20 & 5,22 & 4,85 & 5,00 & 5,03 & 5,27 & 5,00 \\
\hline SSD $05^{\mid 79}$ & \multicolumn{7}{|c|}{0,15} \\
\hline
\end{tabular}

* Average size pHkcl. in the period of laying of experiment in 1971 year 6.2 equaled.

The size of hydrolytic acidity $\left(\mathrm{H}_{\mathrm{r}}\right)$ indicates gradual increase in potential acidity of the soil in time and from fertilizers. So, in control in 1992 year equaled 2,46 mmol (ekv) of/100 $\mathrm{g}$ and in the 2006-th $-3,92$, against the background of N75-60P in the same years $-3,05$ and 4,75 .

The amount of absorbed calcium and magnesium from fertilizers did not change in comparison with the control, nor did it change over time (tab. 6).

Table 6. Influence of Fertilizer on the Sum of $\mathrm{Ca}$ and $\mathrm{Mg}$

in the lixivious chernozem $(0-20 \mathrm{~cm}), \mathrm{mmol}(\mathrm{ekv}) / 100 \mathrm{~g}$.

\begin{tabular}{|l|c|c|c|c|c|}
\hline Year / Variant & 1990 & 1992 & 1993 & 2006 & 2010 \\
\hline Control & 20,4 & 19,6 & 21,7 & 21,7 & 19,0 \\
\hline N25-20P & 21,2 & 19,5 & 22,4 & 21,1 & - \\
\hline
\end{tabular}




\begin{tabular}{|l|c|c|c|c|c|}
\hline N50-40P & 22,1 & 18,8 & 22,9 & 22,0 & - \\
\hline N75-60P & 21,0 & 18,8 & 21,8 & 22,6 & 22,8 \\
\hline
\end{tabular}

Fertilizers had a more noticeable effect on the content of mobile nutrients. Table 7 shows the content of $\mathrm{P}_{2} \mathrm{O}_{5}$ according to Chirikov in the soil layer of $0-20 \mathrm{~cm}$ on the sowing of permanent wheat. Without fertilizers, at the initial value of $40 \mathrm{mg} / \mathrm{kg}$, fluctuations in the range of $36-50 \mathrm{mg} / \mathrm{kg}$ were noted, with an average of 47 . In plots where one nitrogen fertilizer was used annually for 50 years, the $\mathrm{P}_{2} \mathrm{O}_{5}$ content decreased to $32-45 \mathrm{mg} / \mathrm{kg}$, an average of 41 . In the NR variant, since 2008, in addition to the aftereffect of P40 introduced in the crop rotation for 25 years - in the amount of P1000, P20 was added, that is, the amount of phosphorus applied by the spring of 2020 was P1240. Here, the accumulation of $\mathrm{P}_{2} \mathrm{O}_{5}$ in the arable soil layer increased to $77-112 \mathrm{mg} / \mathrm{kg}$, on average to 83 . Comparison of the content of mobile phosphorus and crop yield by variant clearly shows their close relationship in the soil, poor in phosphates. The use of the content of mobile $\mathrm{P}_{2} \mathrm{O}_{5}$ in the soil is sufficiently reliable for the selection of fields where it is necessary to apply phosphorus fertilizer. With the close interaction of nitrogen and phosphorus, phosphorus fertilizer is effective only on the backgrounds of good nitrogen supply of plants (by steam, and after other precursors when applied together with nitrogen fertilizer). Indeed, the unilateral application of P20 in our experience in the crop rotation without steam and on permanent wheat over a 50 -year period increased the yield only in $16 \%$ of the years.

Table 7. Content $\mathrm{P}_{2} \mathrm{O}_{5}$ in the soil layer of $0-20 \mathrm{~cm}$ on a stubble background, $\mathrm{mg} / \mathrm{kg}$.

\begin{tabular}{|l|c|c|c|c|c|}
\hline \multicolumn{1}{|c|}{ Years/ Variant } & $2009-2012$ & $2013-2016$ & $2017-2020$ & 2020 & Average \\
\hline Control & 50 & 43 & 48 & 36 & 47 \\
\hline N40-60P0 & 39 & 45 & 39 & 32 & 41 \\
\hline N40-60ПP40+P20 & 77 & 87 & 84 & 112 & 83 \\
\hline SSD 05 & $12 ;$ Ffact 54,92; Ftable 4,75 \\
\hline
\end{tabular}

The amount of nitrates in a meter layer of soil in the spring in early May before fertilizing (the residual amounts of fertilizers were determined on the backgrounds of their regular use) was on average $45 \mathrm{~kg} / \mathrm{ha}$ in the control and 74 against the background of N4060P20 (Table 8). At the doses of nitrogen on the phosphorus background, the accumulation of nitrate nitrogen more often approached to optimum $(80 \mathrm{~kg} /$ ha in a meter layer of soil).

Table 8. Content of $\mathrm{N}-\mathrm{NO}_{3}$ in the meter layer of soil, $\mathrm{kg} / \mathrm{ha}$.

\begin{tabular}{|l|c|c|c|c|c|c|}
\hline Years/ Variant & 2015 & 2017 & 2018 & 2019 & 2020 & Average \\
\hline N0P0 & 35 & 54 & 41 & 48 & 48 & 45 \\
\hline N40-60P20 & 110 & 82 & 53 & 54 & 69 & 74 \\
\hline SSD $_{05}$ & \multicolumn{7}{|l|}{} \\
\hline
\end{tabular}

Sometimes the amount of nitrate nitrogen was low and close to control, which is explained by a very cool May with a decrease in air temperature in the 2nd decade to 9.6$11.7^{\circ} \mathrm{C}$, as observed in 2018 and 2019.A small amount of nitrate nitrogen in the meter layer could be after its partial lowering with precipitation in layers below a meter, which is proved by a uniform distribution of nitrates in layers of $20 \mathrm{~cm}$ to a depth of 1 meter, as well as an increased amount in the layer of $80-100 \mathrm{~cm}$, as can be seen in Figure 1 by definition in spring 2020 year.

The washing of part of the nitrates into the lower layers of the soil is confirmed and by the observation of 2015, when samples were taken to a depth of 3 meters. Nitrate nitrogen losses in the lower soil layers of $60-300 \mathrm{~cm}$ differed in versions. It should be noted that the lowering of nitrates below $60 \mathrm{~cm}$ turned out to be more noticeable in the N40 without phosphorus version compared to their joint use (Figure 2). The use of the same dose of nitrogen N40 without phosphorus fertilizer by plants was less active. 


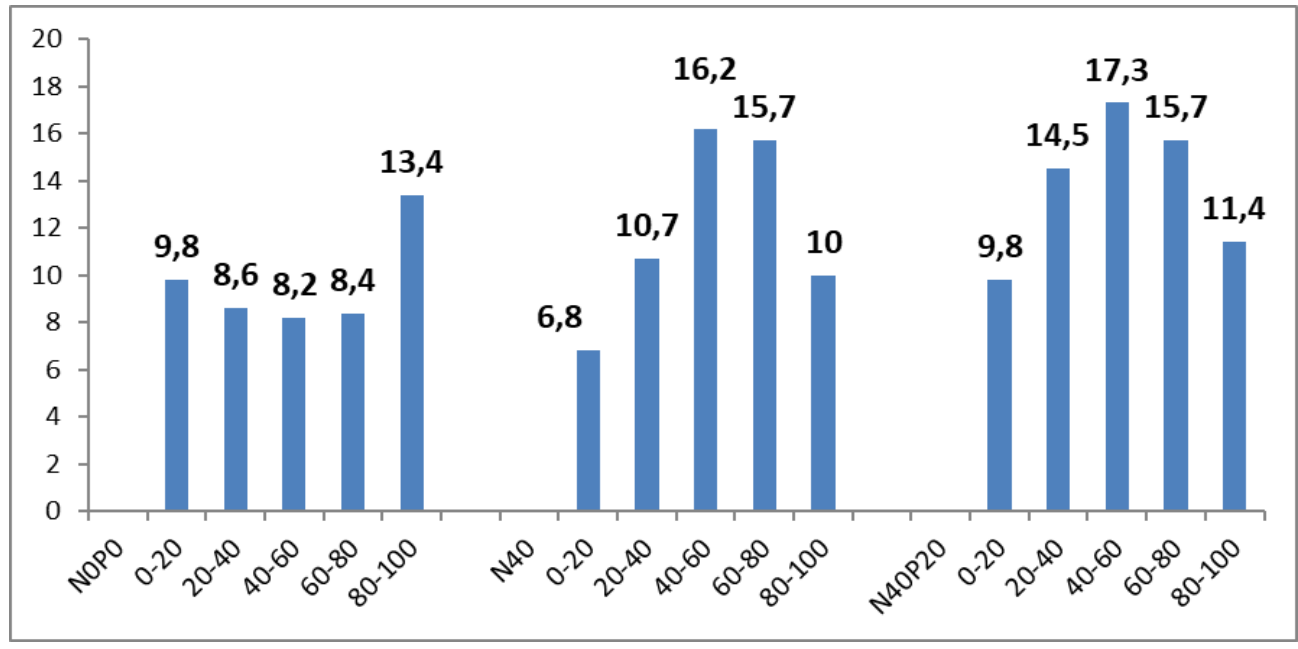

Fig. 1. The content of N-NO3 on May 4, 2020 by layers of $20 \mathrm{~cm}$ to a depth of $1 \mathrm{~meter}, \mathrm{~kg} / \mathrm{ha}$, the sums for the layer 0-100 cm in three variants were: N0P0-48,4; N40-59,4 and N40P20-68,7.

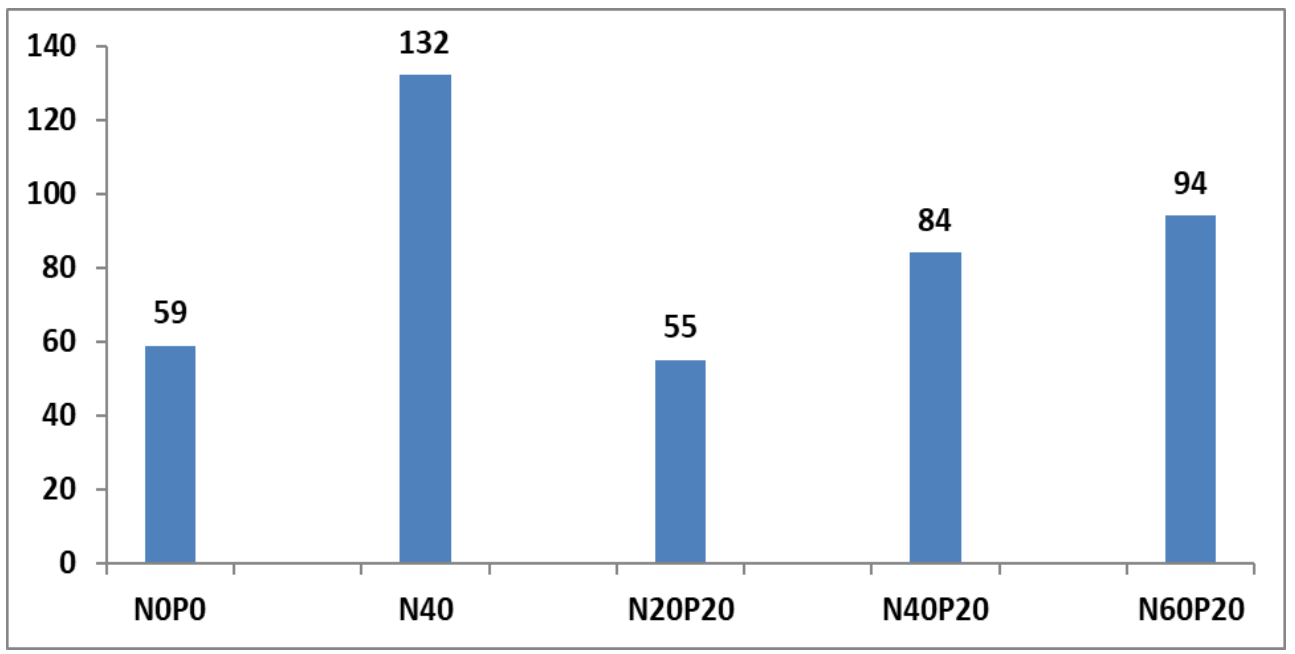

Fig. 2. Amount of N-NO3 dropped into soil layer 60-300 cm, kg/ha, 2015 year.

Two of these reasons - the dependence of nitrate accumulation on air temperature and heavy precipitation makes it less reliable to diagnose the need for nitrogen only by the content of nitrates, and even when recommending a layer of 0-40 cm. It is necessary to combine the results on nitrates for the meter layer, taking into account the previous crop, its fertilization, as well as with the conclusions of the field stationary experience in conditions similar to economic ones.

The availability of plants with mobile potassium in the area under experience is high in all versions. The layer 0-20 cm contains $226-353 \mathrm{mg} / \mathrm{kg} \mathrm{K} 2 \mathrm{O}$ according to Chirikov. The high security class includes readings above $180 \mathrm{mg} / \mathrm{kg}$. In some years, the trend of decreasing soil $\mathrm{K}_{2} \mathrm{O}$ in fertilized plots was viewed, where potassium removal is higher due to increased yields. 


\section{Discussion}

The high informativeness of the stationary experiment allows us to build curves of crop responsiveness to the tested doses of fertilizes, to set optimal dose levels, to compare the yield with the indices of plant nutrient availability. This data becomes the basis of a knowledge base for the subsequent preparation of an expert-advisory program, with the help of which it is possible to advise agricultural specialists on the use of cost-effective doses of fertilizers for conditions identical to the experience.

\section{Conclusion}

The effective fertility of leached chernozem in a stationary experiment at the Central Experimental Field of the Kurgan NIISX was characterized by a higher productivity of agrocenosis, represented by crop rotation of corn-wheat-wheat-oats at annual plowing compared to agrocenosis of permanent wheat for stubble. The effect of the fertilizer composition on crop yields in both agrocenoses was highly positive, provided that nitrogen was used in combination with phosphorus, since the soil was poor in mobile phosphorus. A higher yield with a better payback of fertilizer was distinguished and also decrease loss of nitrates from washing by the N40P20 option.

The agrochemical properties of the soil in a number of versions of the experiment on fertilized backgrounds changed in the direction desired for the farmer. The positive influence was the use of the 2 nd and 3rd doses of nitrogen with phosphorus, it improved the fertility of the soil in terms of the amount of mobile nutrients and the content of humus. On average, over the 50 years of experience, the balance of humified organic matter turned out to be positive in all variants with fertilizers, but differed in size in favor application of the N40-50P40-20.

In control, the acidity of the soil in time to the initial value of pHkcl 6,2 increased by 2020 to an average acid of 5,2. Fertilizer N75-60R increased acidity to a value of pHkcl by 2020 to 5,0 .

In order to diagnose the need of plants for phosphorus fertilization, it is acceptable to use the determination of the content of mobile $\mathrm{P}_{2} \mathrm{O}_{5}$ in the soil layer $0-20 \mathrm{~cm}$. For solutions to the need of crops for nitrogen, it is convenient to use a set of indicators: the content of N$\mathrm{NO}_{3}$ in the meter layer of soil, the accounting of the precursor, its fertilization and the results of field stationary experience in the analogous condition for which the solution is being sought.

\section{Acknowledgements}

I would like to express my gratitude to the managers of research V. I. Volynkin, A. N. Kopylov and the group that took part in the work on the experience.

\section{References}

1. N.N. Shapovalova, E.P. Shustikova, Influence of long-term use and consequences of different types and doses of mineral fertilizers on the agrochemical properties of ordinary chernozem, Materials of the All-Russian Meeting of Scientific Institutions Participants in the Geographical Network of Fertilizer Experiments on October 6, 2016, M.: VNIIA, 314-321 (2016)

2. M.P. Chub, V.V. Pronko, L.B. Sayfulina, T.M. Yaroshenko, N.F. Klimova, Agrochemistry, 7, 3-13 (2010) 
3. L.V. Pomazkina, Yu.V. Semenov, A.A. Simakova, N.N. Kirillova, I.A. Bashalkhanov, Agrochemistry 5, 65-71 (2016)

4. G.Ya. Chesnyak, F.Ya. Gavrilyuk, I.A. Krupenikov, N.I. Laktionov, N.A. Shilikhina, Gumusovoye state of chernozems, Russian chernozem 100 years after Dokuchaev, 186198 (M., Publishing House "Science," 1983)

5. V.G. Sychev, L.K. Shevtsova, G.E. Merzlaya, Agrochemistry 2, 3-21 (2018)

6. A.A. Novikov, Scientific Journal of the Russian Research Institute of Land Reclamation Problems 2 (26), 131-143 (2017)

7. A.N. Voronin, V.D. Solovichenko, V.N. Samykin, A.A. Potryasoev, Fertility 1 (52), 34-35 (2010)

8. A.I. Thunderbolt, V.A. Korolev, Agrochemistry, 12, 10-15 (2014)

9. I.N. Sharkov, A.A. Danilova, Agrochemistry 12, 72-81 (2010)

10. N.A. Chuyan, G.M. Breskina, Agrochemical bulletin 3, 35-39 (2018)

11. V.G. Kholmov, M.I. Shulyakov, Improvement of agricultural technologies of grain on the chernozems of the forest-steppe of Western Siberia, Modern problems of soil protection agriculture and ways to increase the stability of grain production in the steppe regions, 102-106 (Shortands, 1, 2006)

12. L.A. Nechaev, G.N. Cherkasov, V.I. Koroteev, Agrochemistry 1, 3-17 (2013)

13. M.S. Sokolov, A.P. Glinushkin, Yu.Ya. Spiridonov, E.Yu. Toropova, O.D. Filipchuk, Agrochemistry 5, 3-20 (2019)

14. P.P. Vasyukov, G.M. Lesovaya, G.V. Chuvarleeva, A.A. Mnatsakanyan, O.B. Bykov, M.T. Mukhina, Fertility 3 (102), 17-20 (2018)

15. A.A. Dedov, A.V. Dedov, M.A. Nesmeyanova, Agrochemistry 6, 3-8 (2016)

16. E.N.Belousova, Bulletin of the Tomsk State Agrarian University, Biology 1, 7-25 (2014)

17. V.G. Sychev, Main yield resources and their interrelation, 228 (M: TsINAO, 2003)

18. A. G.Shepelev, L.M .Samokhvalova, Bulletin of the Tomsk State Agrarian University, Biology 37, 6-16 (2017) 